\title{
An Evaluation of Irradiation Treatment to Disinfect Soil Tare from Globodera spp.
}

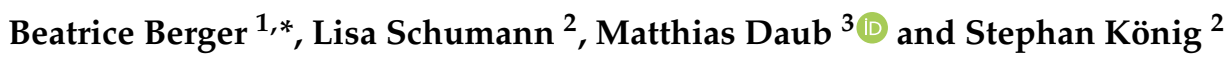

1 Julius Kühn Institute (JKI)-Federal Research Centre for Cultivated Plants, Institute for Plant Protection in Field Crops and Grassland, Messeweg 11/12, 38104 Braunschweig, Germany

2 Julius Kühn Institute (JKI) - Federal Research Centre for Cultivated Plants, Institute for National and International Plant Health, Messeweg 11/12, 38104 Braunschweig, Germany; lisa.schumann@julius-kuehn.de (L.S.); stephan.koenig@julius-kuehn.de (S.K.)

3 Julius Kühn Institute (JKI) - Federal Research Centre for Cultivated Plants, Institute for Plant Protection in Field Crops and Grassland, Dürener Str. 71, 50189 Elsdorf, Germany; matthias.daub@julius-kuehn.de

* Correspondence: beatrice.berger@julius-kuehn.de

Citation: Berger, B.; Schumann, L.; Daub, M.; König, S. An Evaluation of Irradiation Treatment to Disinfect Soil Tare from Globodera spp. Agronomy 2022, 12, 464. https://doi.org/ 10.3390 /agronomy12020464

Received: 21 January 2022

Accepted: 11 February 2022

Published: 13 February 2022

Publisher's Note: MDPI stays neutral with regard to jurisdictional claims in published maps and institutional affiliations.

Copyright: (C) 2022 by the authors. Licensee MDPI, Basel, Switzerland. This article is an open access article distributed under the terms and conditions of the Creative Commons Attribution (CC BY) license (https:// creativecommons.org/licenses/by/ $4.0 /)$.

\begin{abstract}
As a severe danger to potato plants, potato cyst nematodes (PCNs) are regulated quarantine pests in many countries. Adhering soils to potato or other tuber crops provoke the uncontrolled spread of the pest after their industrial processing. The disinfection of soil tares to inactivate PCNs is therefore compulsory. In the present study, we test whether the viability and formation of $\mathrm{PCN}$ cysts are suppressed after treatment with $\gamma$ and $\beta$ irradiation. In a first experiment, nematode cysts were treated with $\gamma$ or $\beta$ irradiation without soil matrix to determine the minimum dose parameters in a range between 0-12 kGy. Subsequently, two representative soils that included cysts were irradiated. Irradiation effects on PCN viability and the formation of new cysts were evaluated via hatching tests and bioassays with susceptible potato plants, respectively. In addition, maize seedling growth was tested in irradiated soil tares. We found that next to $\gamma$ also, $\beta$ irradiation suppressed the hatch of PCN juveniles and its formation of cysts when placed in soil tares. The growth of maize seedlings was not impaired in irradiated soils compared to control soils. Both $\gamma$ and $\beta$ irradiation treatment offer an organism group selective and effective phytosanitary measures to disinfect soil tares from PCNs.
\end{abstract}

Keywords: quarantine pest; soil tare; potato cyst nematodes; $\gamma$ and electron beam irradiation; phytosanitary measures

\section{Introduction}

The potato cyst nematodes (PCNs) Globodera pallida (Stone, 1973) and G. rostochiensis (Wollenweber, 1923) are severe pests, mainly in potatoes (Solanum tuberosum L.), but also in other solanaceous species (EPPO 2017) $[1,2]$. The presence of the pests $[3,4]$ and arising economic losses are described in all areas where potatoes are cultivated [5,6]. Damage symptoms on potato plants, such as patches of stunted plant growth and yellowing of leaves, are rather unspecific and become visible at a late stage. Once PCN populations have been established, eradication in the field is challenging since effective nematicides are not available. The breeding of resistant potato cultivars is a major strategy to eradicate the pest in infested field sites [7]. Nevertheless, new Globodera spp. populations with high virulence breaking all known resistances in potato cultivars can emerge at any time and cause severe damage [8]. Therefore, preventing the spread pathways of the two species is one of the major management tasks for potato cultivation. Plant health control regulations were already established to diminish the risk from spreading cysts via planting potato material [9]. However, soil tares adhering to harvested potatoes or other tuber crops are still an unpredictable source of nematode cysts. Uncontrolled returns of pooled and non-disinfected soil tares to arable land may dramatically increase the risk of PCN spread. Indeed, an immense amount of soil tares accumulates each year in the E.U., 
approximately 700,000 tons only in Germany (Bundesverband der obst-, gemüse- und kartoffelverarbeitenden Industrie e.V., personal communication, 2017). As quarantine pests, PCNs are listed in Appendix II of Directive 2019/2072, part B, and are subjected to notification. On the other hand, increasing the amount of soil tares that are not reused would result in a dramatic constant loss of arable land.

During their development, female PCNs enlarge to a sedentary dormant cyst, which can persist for more than twenty years in the soil $[10,11]$. Challenges to desinfect soils targeting PCNs are, on the one hand, to overcome the cyst wall protective barrier to reach vulnerable eggs and juveniles with effective measures before hatching and release of J2 from the cysts, and in addition facing a complex soil matrix that interferes with disinfection treatments.

Disinfection measures, such as $\gamma$ and $\beta$ irradiation, already play an important role in the decontamination of packing material or medical disposables, from a wide range of pathogens and pests [12-14]. In the food industry, irradiation treatment prolongs storage capability or inhibits the spore germination of fungi. The energy density absorbed by the material is given with the dose unit Gray (Gy), where $1 \mathrm{~Gy}$ is defined as the energy of 1 joule transferred to a mass of $1 \mathrm{~kg}$ in a field of ionising irradiation with constant energy flux density [15]. The treated material itself does not become radioactive, because the irradiation does not contain any radioactive atoms or particles, and the exposed material is not in contact with the radiation source.

Ionised irradiation may cause single and double strand breaks of the DNA in chromosomes by free radicals, active oxygen species and peroxides [16], which can be mutagenic or lethal. The application of ionised irradiation results in primary and secondary effects. The primary effects are ionisation, dissociation and excitation of material caused by quantum energy packages $[17,18]$. The secondary effects are the recombination of ion electrons; ion-molecule reaction and the formation of free radicals that subreact in followup processes [19]. Free radicals remain active over longer distances, capable of damaging biologically relevant molecules, such as DNA, proteins, carbohydrates and lipids [20].

Lethal doses vary among organisms; fungi and invertebrates appear more sensitive to $\gamma$ irradiation, whereas bacteria seem to be resistant up to $25 \mathrm{kGy}[16,21,22]$. Several studies also investigated the impact of $\gamma$ irradiation on nematodes. Measures were shown to work well on free-living nematodes [23-25] via the impairment of spermatogenesis [26], or by increasing the portion of small male adults in the population [27], but the sensitivity to $\gamma$ irradiation varied between different nematode species and G. rostochiensis appeared to be more susceptible than Heterodera schachtii $[23,28,29]$. The $\gamma$ irradiation of eggs and $\mathrm{J} 2$ juveniles of root-knot nematodes Meloidogyne javanica with $4.25 \mathrm{kGy}$, inhibited gall formation and nematode reproduction when applied on tomato plants [24].

The $\gamma$ irradiation, generated by the decay of the radioisotope cobalt- 60 , has a high penetration capability that allows for application of phytosanitary measures also on protective organic material, such as nematode cyst walls, as shown for G. rostochiensis and $H$. schachtii cysts $[29,30]$. In nature, nematodes appear in plants or in soils, such as tare soils. In particular, studies on the irradiation of nematode cysts within soils are rare and limited to $\gamma$ irradiation treatment.

Townshend reported on $\gamma$ irraditated field soil infested with $H$. schachtii at non-lethal doses of $1.28 \mathrm{kGy}$, and that the extracted juveniles from this soil failed to form cysts [29]. Karnowski and colleagues demonstrated an impaired development of natural soil abundant G. rostochiensis (Ro1 pathotype) with less cysts after $\gamma$ irradiation treatment of soils with $3 \mathrm{kGy}$. Unfortunately, the number of initial cysts in the soils was only estimated [31].

The $\beta$ irradiation uses high-energy electron streams that are accelerated to near the speed of light within an electric field. This electron beam generating process can take place within minutes, which allows minimising oxidation effects, but also has lower possible material impacts than $\gamma$ irradiation. Nevertheless, compared to $\gamma$ irradiation, $\beta$ irradiation has a moderate-to-low penetration rate on compact material with a high density. However, biocide effects are known and the tailored treatment of wheat seeds against fungal 
pathogens in the pericarp and the testa are described [32]. How effective electron beam irradiation works against PCNs and especially against those fixed within a soil matrix, such as in tare soils, is, to date, unknown.

A knowledge gap also exists concerning the impact of irradiation on PCNs in different soil types and soil textures. A study about the effect of $\gamma$ irradiation on the abundance of free-living nematodes and other soil biota in different soil types was published, but cyst nematodes were not considered [33].

Therefore, depending on the field site and the plant culture, which is processed, soil tare mixtures differ in soil organic matter and humidity content, and, as a consequence, irradiation effects on PCNs might be more or less intense. On the other hand, both irradiation forms may also affect soil properties and soil microbial communities in a detrimental way. While there is no data on $\beta$ irradiation, the effects of acute $\gamma$ irradiation were tested on the chemical, physical and biological properties of soils [34]. Soil organic matter content influences the release of $\mathrm{N}$ and $\mathrm{P}$ during the irradiation processes, and sandy soils, for example, are less affected by $\gamma$ irradiation than loamy ones. However, the cation-exchange capacity, which expresses the soil's ability to supply cation nutrients to plants, was not significantly altered by $\gamma$ irradiation [35].

Soil biota, such as bacteria and fungi, are strongly associated with plant performance. Ogwu and colleagues drew a correlation between $\gamma$ irradiation of soils with a decreasing diversity in bacteria and, vice versa, an increasing diversity in fungal communities [36]. However, how treated soils might influence plant growth needs to be clarified before the soil can be returned to the field sites. Crop rotation with sugar beet or maize are common for potato plants and an impaired soil capacity with respect to its nutrient availability could negatively affect the growth of following crops.

Therefore, the aim of the study is to: (i) determine the lowest dose of $\gamma$ and $\beta$ irradiation, which successfully inhibit the hatch and the formation of new PCN cysts, respectively; (ii) determine the impact of a soil tare from the potato processing industry on the effect of $\gamma$ and $\beta$ irradiation on the PCN disinfection process; and (iii) test the impact of irradiated soil on maize seedling germination and growth rates.

\section{Materials and Methods}

\subsection{Potato Cyst Nematodes}

Reference nematode cysts of the G. pallida population "Kalle" and G. rostochiensis population "Harmerz" were originally collected in the late 1980s in northern Germany (Dr. B. Niere, personal communication, 2016). Resistance selection for G. pallida pathotype 2 (Pa2) and for G. rostochiensis pathotype 5 (Ro5) were then performed on resistant potato cultivars. These populations serve as standard nematode populations and were multiplied at the facilities of the Julius Kühn Institute in 2019 using the completely susceptible potato variety "Desiree". Newly formed cysts were then kept at $4{ }^{\circ} \mathrm{C}$ for at least three months to mimic a diapause before further use in experiments. After that period, cysts were categorised by size $(>500 \mu \mathrm{m})$, and injured cysts were discarded. For distinct control, DNA was extracted and identification was conducted according to the EPPO DNA barcoding standard [37]. The obtained PCR products were sequenced and the sequences were aligned with data from NCBI (https: / / www.ncbi.nlm.nih.gov/, 15 Janurary 2022) and EPPO-Qbank Nematodes database (https:/ / qbank.eppo.int/nematodes, 15 Janurary 2022).

\section{2. $\gamma$ and $\beta$ (Electron Beam) Irradiation Treatment}

The $\gamma$ irradiation and $\beta\left(\beta^{-}, \beta^{+}\right.$, electron beams) irradiation at $0,1,4,8$ and $12 \mathrm{kGy}$ doses were performed under controlled conditions at the Synergy Health Radeberg GmbH, (Radeberg, Germany) by trained staff. In detail, an electron beam irradiation facility GSE 80 with an accelerator type Rhodotron TT 300 (3/10 MeV) and the $\gamma$ irradiation facility GS 3000 with an irradiation source nuclide Co-60 were utilised for the different treatments. During the sample treatments, an Alanin ESR dosimeter was placed on top of the boxes, which recorded the received dose, and served as a control for the successful application of 
the required doses. For $\beta$ irradiation, a $10 \mathrm{MeV}$ was applied and the desired $\mathrm{kGy}$ amount of $1,4,8$ or $12 \mathrm{kGy}$ was regulated by the speed of the beam carrier.

In a first approach, 100 intact G. pallida or G. rostochiensis cysts were sealed with a bag sealer (Allpax GmbH \& Co. KG, Papenburg, Germany) in permeable $2.5 \times 2.5 \mathrm{~cm}$ nylon gaze sachets $(200 \mu \mathrm{m}$ mesh size). Four individual mesh bags per species, dose and irradiation source were treated, respectively. First, the cyst sachets were fixed at the bottom of a paper box and then the box was sealed. To exclude the possible effects of cyst damage during the transport to the irradiation facilities, a control box with cysts was shipped simultaneously.

In a second approach, cyst sachets with 100 cysts were placed in soil tares from the potato processing industry. We analysed two types of mixed soil tares representing two typical potato growing regions in Germany: soil tare mixture, "Emsland", from Lower Saxony (Emsland) is a mixture of grey-brown podzolic soil and soil tare mixture, "Donaumoos", from Bavaria (Donaumoos) is a mixture of mineralised turf soil with a high organic percentage. Each paper box contained $500 \mathrm{~g}$ of soil. The sachets were placed in the centre and covered with soil $2.5 \mathrm{~cm}$ above and $2.5 \mathrm{~cm}$ below. Boxes with soil and cysts were exposed to 1,4 or $8 \mathrm{kGy}$ of $\gamma$ irradiation or $\beta$ irradiation, respectively. All the treated cysts were further tested for their viability and multiplication rates, and compared to untreated control samples.

\subsection{Hatching Test of the Exposed Cysts}

The hatching test proves the viability of the eggs and juveniles within the whole cysts. The test was performed according to the EPPO Standard PM 7/40 [1]. Twenty randomly selected cysts per treatment and replicate (four replicates per treatment) were chosen and exposed to $1 \mathrm{~mL}$ potato root diffusates (v:v, 1:2, root diffusate: water) collected from the susceptible potato cultivar "Desiree" (Agropa GmbH, Brunnen, Germany). Every seven days, the newly emerged juveniles per batch were counted, discarded and the diffusates were renewed. The total sum of hatched juveniles was monitored over a period of seven weeks and compared to the hatching of $\mathrm{J} 2$ from non-treated control cysts.

\subsection{Bioassay-Formation of New Cysts}

To test the capability of the treated cysts to release vital juveniles that form new cysts on potato plants, we performed in vivo bioassays. In detail, the potato tubers of the susceptible potato variety, "Desiree", were germinated in the dark at $20^{\circ} \mathrm{C}$ for about ten days until the first sprouts were visible. After germination, the potatoes were transferred to Teku ${ }^{\circledR}$ pots $(9 \times 9 \times 10 \mathrm{~cm})$ (Pöppelmann $\mathrm{GmbH} \&$ Co. KG, Lohne, Germany) half filled with pure loess loam that was free from nematode cysts. Osmocote ${ }^{\circledR}$ Exact Standard 5-6 M (ICL Speciality Fertilizers, Nordhorn, Germany) was added as a fertiliser in the concentration of a $1.5 \mathrm{~g} \mathrm{~kg}^{-1}$ substrate. Next to the tuber, a gaze sachet with 50 cysts was placed. The sachets contained cysts either from treated samples from the first experiment (cysts without soil) or from the second experiments (cysts with soil), or from non-treated cysts that served as controls. Finally, the pot was filled up with substrate. Each pot was placed on a single trivet to avoid nematode transfer between the pots. Plants were kept at $20{ }^{\circ} \mathrm{C} / 16{ }^{\circ} \mathrm{C} 16 \mathrm{~h} / 8 \mathrm{~h}$, under natural light conditions and were watered on demand. The soil temperature was recorded over the whole cultivation period of 15 weeks, to ensure that a required daily temperature sum of $1800^{\circ} \mathrm{C}$ was achieved [38]. Then, irrigation was stopped, the aboveground tissue was cut off and the substrate in the pots was washed through a mesh sieve with a width of $250 \mu \mathrm{m}$ (RETSCH GmbH, Haan, Germany). The sieve allowed for the holding back of the newly formed cysts. The newly formed cysts were counted and the cyst formation rate was calculated as $P_{f} / P_{i}$ quotient, where $P_{f}$ represents the final number and $P_{i}$ the initial number of cysts present in the pot. $A P_{f} / P_{i}$ quotient higher than one represents an augmentation in cysts [1]. Four pots with cysts per treatment and controls were used and arranged in a randomised design. 


\subsection{Maize Pot Experiment}

Potato plants are commonly grown in rotation with other crops, such as maize. In this case, the return of treated tare soils from potato processing might affect the growth of maize, which is then cultivated in the same field. To determine the effect of $\gamma$ and $\beta$ irradiated soil on plant emergence and growth rates, we cultivated maize (Zea mays L.) of the "Ricardinio" variety (KWS SAAT SE \& Co. KGaA, Einbeck, Germany) in a greenhouse experiment. Jiffypots ${ }^{\circledR}$ (diameter: $6 \mathrm{~cm}$ ) (Jiffy, Oslo, Norway) were filled with treated soil tare mixture "Emsland", or soil tare mixture "Donaumoos", respectively. Non-treated soil tare mixtures served as controls. Soil humidity was present and three maize seeds were sown per pot. Four pots for each radiation treatment and controls were randomly arranged on single trivets. No additional fertiliser was added to pinpoint the direct effects on plant growth by radiation. Pots were kept at $20{ }^{\circ} \mathrm{C}$ and $70 \%$ air humidity. Plants were harvested four weeks after germination and plant material was dried at $80^{\circ} \mathrm{C}$ for $24 \mathrm{~h}$, and the final dry mass of root and aboveground tissue was determined.

\subsection{Statistics}

Data of the hatching tests, bioassays and maize in planta tests were analysed and plotted using the R Version R-4.03 with visualisation in RStudio packages stats and ggplot2. Data from the hatching test and bioassays were analysed post hoc by non-parametric Kruskal-Wallis with the pairwise Wilcoxon post hoc test using adjusted $p$-values, because the data did not fit the normal distribution according to the Shapiro-Wilk test. The shoot and root dry weight data were tested on a normal distribution by the Shapiro-Wilk test, transformed if necessary and analysed post hoc by ANOVA Dunnett's post hoc test.

\section{Results}

\subsection{Hatching of G. pallida and G. rostochiensis Juveniles after Irradiation}

Juvenile stage $\mathrm{J} 2$ hatching data showed the differences between the treatment groups (Kruskal-Wallis test, $\mathrm{chi}^{2}=74.8, \mathrm{df}=19, p<0.001$ ). The viability of the cysts that were directly exposed to $\gamma$ or $\beta$ irradiation doses of $4 \mathrm{kGy}$ and above were sufficiently inactivated in both species, G. pallida and G. rostochiensis were compared to the respective non-treated controls (Figure 1) (Wilcoxon post hoc test, $p<0.05$ ). The $\gamma$ irradiation treatment at a low level of $1 \mathrm{kGy}$ slightly increased the hatch of G. rostochiensis juveniles by $10 \%$ compared to their respective control cysts (Figure 1b), while the hatching of G. pallida in the $1 \mathrm{kGy}$ level was not different from the control (Figure 1a). Concerning the application of $1 \mathrm{kGy} \beta$ irradiation, the trend is different between the species (Wilcoxon post hoc test, $p<0.05$ ). Both PCN species showed a reduced number of hatched juveniles, whereas the number was lowered by more than 20\% in G. rostochiensis (Figure 1d); it was significantly reduced by $70 \%$ in G. pallida (Wilcoxon post hoc test, $p<0.05$ ) (Figure 1c) compared to their respective control samples. We found species and irradiation type-dependent hatch suppression levels at low intensities, while those differences vanished at higher irradiation doses. While $1 \mathrm{kGy}$ of $\gamma$ irradiation did not affect the hatching activity of G. pallida, $1 \mathrm{kGy}$ of $\beta$ irradiation did (Wilcoxon post hoc test, $p<0.05$ ). 


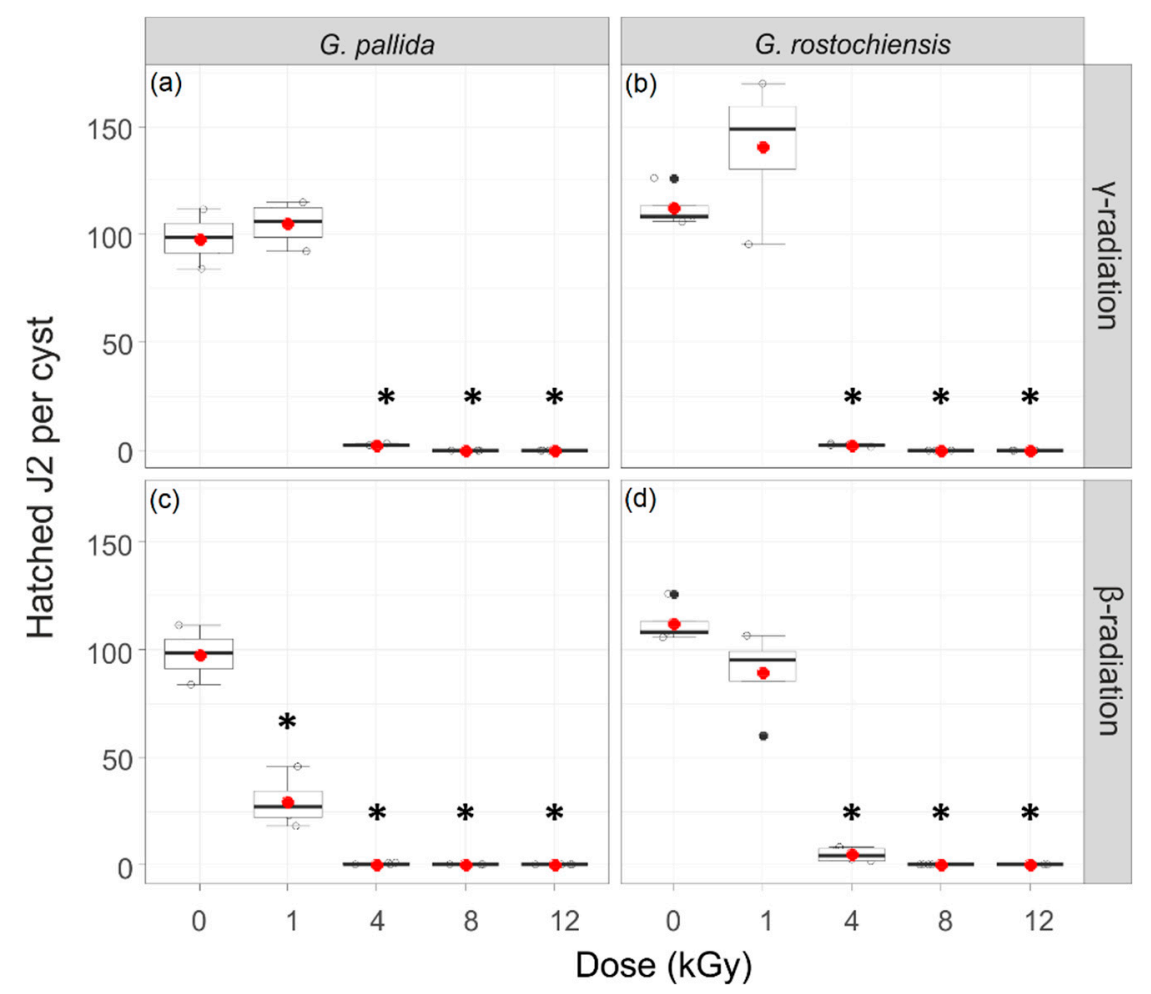

Figure 1. Hatching test for G. pallida and G. rostochiensis $\gamma$ and $\beta$ irradiated cysts. Total number of hatched juveniles (J2) per cyst over a period of seven weeks for $0,1,4,8$ and $12 \mathrm{kGy} \gamma$ irradiated G. pallida (a), $\gamma$ irradiated G. rostochiensis (b), $\beta$ irradiated G. pallida (c) and $\beta$ irradiated G. rostochiensis (d) cysts. Data were analysed by the non-parametric Kruskal-Wallis test with the pairwise Wilcoxon post hoc test using adjusted $p$-values. Box-whisker plots display the median and mean (red dots) values of four replicates with 20 cysts each. Asterisks indicate the significant differences to the respective non-treated controls.

In a second approach, we measured the hatching activity in cysts that were placed in potato soil tare prior to irradiation treatment. Our data showed significant differences between the treatment groups (Kruskal-Wallis test, $\mathrm{chi}^{2}=114.8, \mathrm{df}=31, p<0.001$ ). Low dose levels were accompanied by high hatching activities of cysts embedded in both soil types. In the soil tare mixture "Emsland", even a $\gamma$ irradiation dose of $4 \mathrm{kGy}$ was insufficient to inactivate cysts of both nematode species. At $4 \mathrm{kGy}$, G. pallida cysts kept a hatching activity of $40 \%$ and G. rostochienis of $44 \%$, compared to the respective non-treated controls (Figure $2 \mathrm{~b}$ ). On the other hand, juveniles in all cysts that received $8 \mathrm{kGy}$ doses were dead, indicating that the soil environment did not buffer irradiation and, consequently, the cysts were not fully protected (Wilcoxon post hoc test, $p<0.05$ ). The soil tare type influenced the hatching activity in cysts that received $1 \mathrm{kGy}$ of $\gamma$ irradiation. Interestingly, in soil tare mixture "Emsland", an increase in hatching by $50 \%$ for G. pallida and by $14 \%$ for G. rostochienis can be observed (Figure 2b), whereas $1 \mathrm{kGy}$ of $\gamma$ irradiation suppressed juvenile hatch in G. pallida and in G. rostochiensis by approximately $40 \%$ when the cysts were placed in soil tare mixture "Donaumoos" (Figure 2a). The $\beta$ irradiation resulted in a severe decrease in juvenile hatch by $70 \%$ in G. pallida and by $45 \%$ in G. rostochiensis in soil tare mixture "Donaumoos" as well (Figure 2c) (Wilcoxon post hoc test, $p<0.05$ ). No effect on the number of hatched juveniles compared to non-treated controls was detected for $G$. rostochiensis cysts at a dose of $1 \mathrm{kGy}$ of $\beta$ irradiation, when placed in soil tare mixture "Emsland", while G. pallida showed a reduced hatch by $50 \%$ compared to its respective non-treated controls (Figure 2d) (Wilcoxon post hoc test, $p<0.05$ ). 


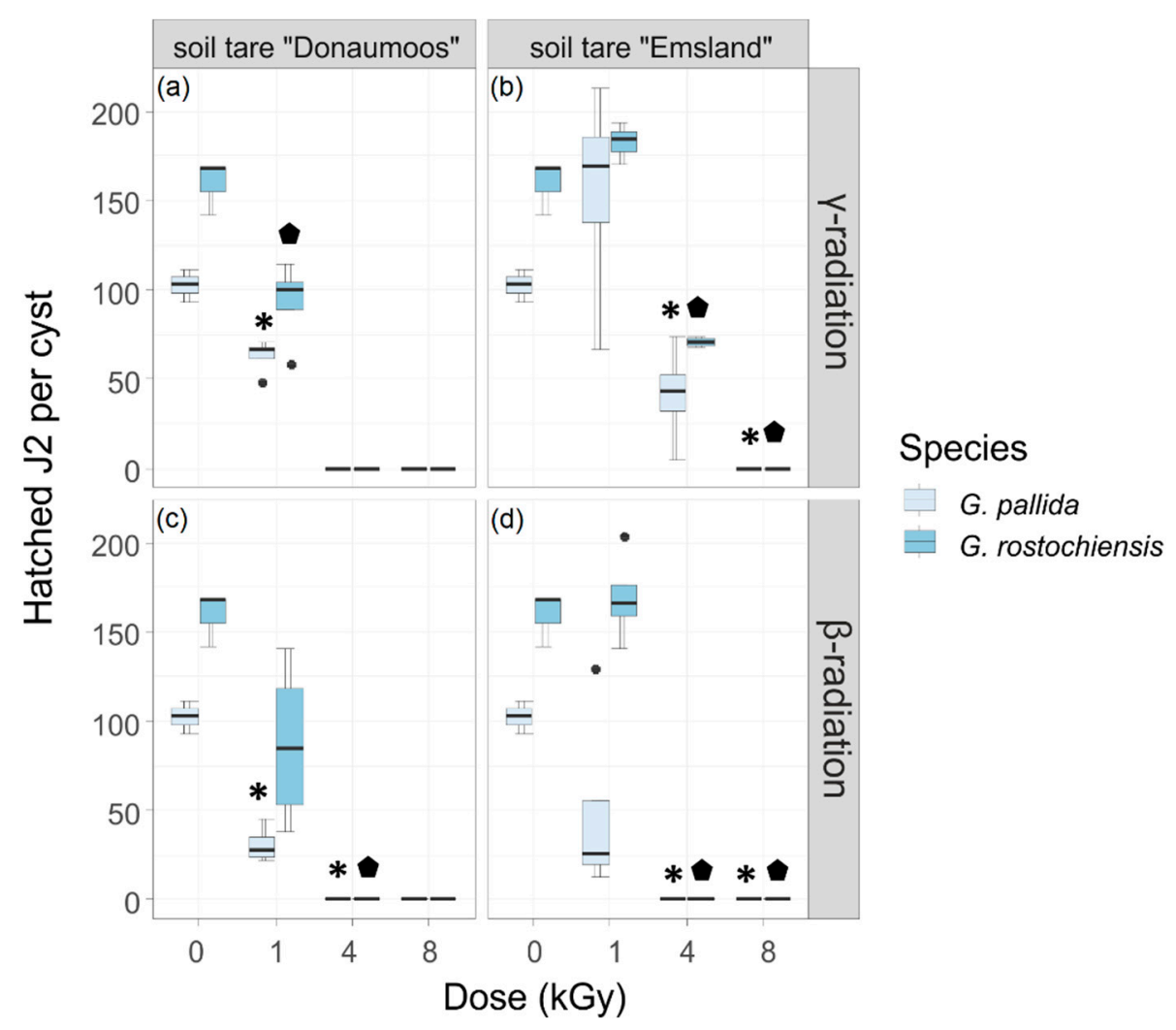

Figure 2. Hatching test for G. pallida and G. rostochiensis $\gamma$ and $\beta$ irradiated cysts in soil tare. Total number of hatched juveniles per cyst over a period of seven weeks for $0,1,4$ and $8 \mathrm{kGy} \gamma$ irradiated G. pallida $(\mathbf{a}, \mathbf{b})$ and G. rostochiensis $(\mathbf{a}, \mathbf{b}), \beta$ irradiated G. pallida and G. rostochiensis $(\mathbf{c}, \mathbf{d})$ cysts placed in soil tare "Emsland" (b,d) and soil tare "Donaumoos" $(\mathbf{a}, \mathbf{c})$. Data were analysed by the non-parametric Kruskal-Wallis test with a pairwise Wilcoxon post hoc test using adjusted $p$-values. Box-whisker plots display the mean values of four replicates with 20 cysts. Asterisks indicate significant differences to the respective non-treated G. pallida and diamonds to the respective non-treated G. rostochiensis controls.

\subsection{Formation of New Cysts after Irradiation Treatment}

All the treated samples were also tested for their ability to form new cysts on a susceptible potato cultivar under controlled greenhouse conditions. Our data showed the differences between the treatment groups (Kruskal-Wallis test, $\mathrm{chi}^{2}=74.3 \mathrm{df}=19$, $p<0.001$ ). Globodera pallida and G. rostochiensis cysts treated with 4,8 or $12 \mathrm{kGy}$ of $\gamma$ or $\beta$ irradiation were not able to form new cysts on potato plants indicated by an $\mathrm{P}_{\mathrm{f}} / \mathrm{P}_{\mathrm{i}}$ ratio below 1, whereas untreated controls were able to reach rates of around 95 (Figure 3 ). Globodera pallida and G. rostochiensis cysts treated with $1 \mathrm{kGy}$ of $\beta$ irradiation were still able to multiply cysts with a $P_{f} / P_{i}$ ratio of 17 (Figure $3 c, d$ ), whereas the $P_{f} / P_{i}$ ratio in 1 kGy of $\gamma$ irradiated samples was approximately two times lower (Figure $3 a, b$ ) compared to the $\beta$ irradiation of the same dose. 


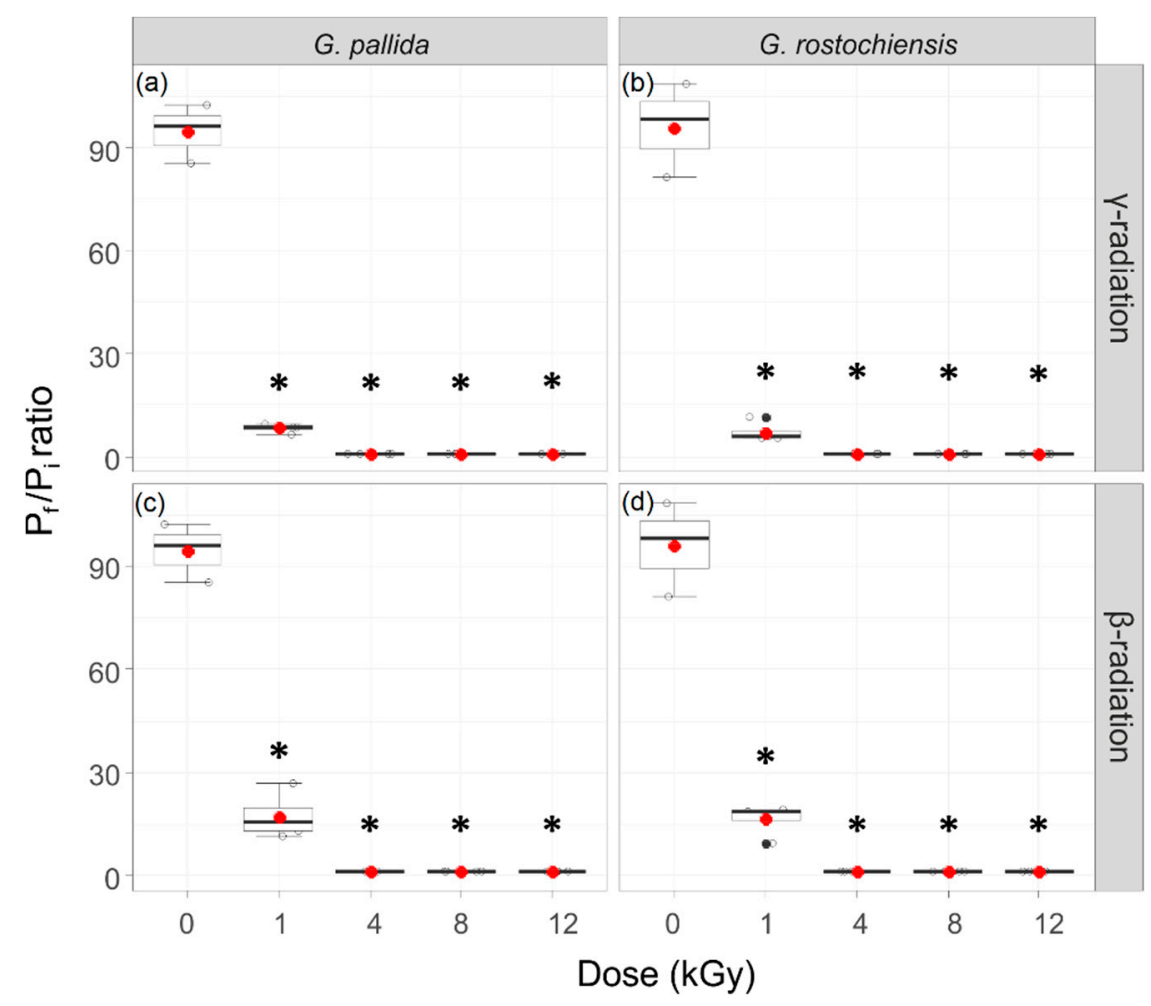

Figure 3. Cyst formation rates of irradiated G. pallida and G. rostochiensis. The ratio of newly formed cysts $\mathrm{P}_{\mathrm{f}}$ (final population) and the number of $\left(\mathrm{P}_{\mathrm{i}}\right)$ initial cysts (50) added to the susceptible potato cultivar "Desiree", 15 weeks after planting. $P_{i}$ cysts were treated with $0,1,4,8$ and $12 \mathrm{kGy}$ of $\gamma$ irradiation $(\mathbf{a}, \mathbf{b})$ or $\beta$ irradiation $(\mathbf{c}, \mathbf{d})$. Data were analysed by the non-parametric Kruskal-Wallis test with a pairwise Wilcoxon post hoc test using adjusted $p$-values. Box-whisker plots display the median and mean (red dots) values of four replicates. Asterisks indicate the significant differences to the respective non-treated controls.

No new cyst formation of G. pallida and G. rostochiensis was found in those cyst samples that were placed in soil tares and treated with either 4 or $8 \mathrm{kGy}$ of $\gamma$ or $\beta$ irradiation (Figure 4). Our data showed the differences between the treatment groups (Kruskal-Wallis test, $\mathrm{chi}^{2}=124.2, \mathrm{df}=31, p<0.001$ ). At $1 \mathrm{kGy}$ of $\beta$ irradiation, cyst formation rates in PCNs are slightly increased in the cyst samples from both soil tares, compared to the hatching rates of cysts treated with doses of $4 \mathrm{kGy}$ or higher (Figure $4 \mathrm{c}, \mathrm{d}$ ), whereas $1 \mathrm{kGy} \gamma$ irradiation shows no suppressive effect on the formation rates in cyst samples of G. pallida from tare soil mixture "Emsland", and only 25\% suppression in G. rostochiensis (Figure 4b). In the cyst samples from soil tare mixture "Donaumoos", similar cyst multiplication ratios can be observed for $\beta$ and $\gamma$ irradiation (Figure $4 a, c)$. 


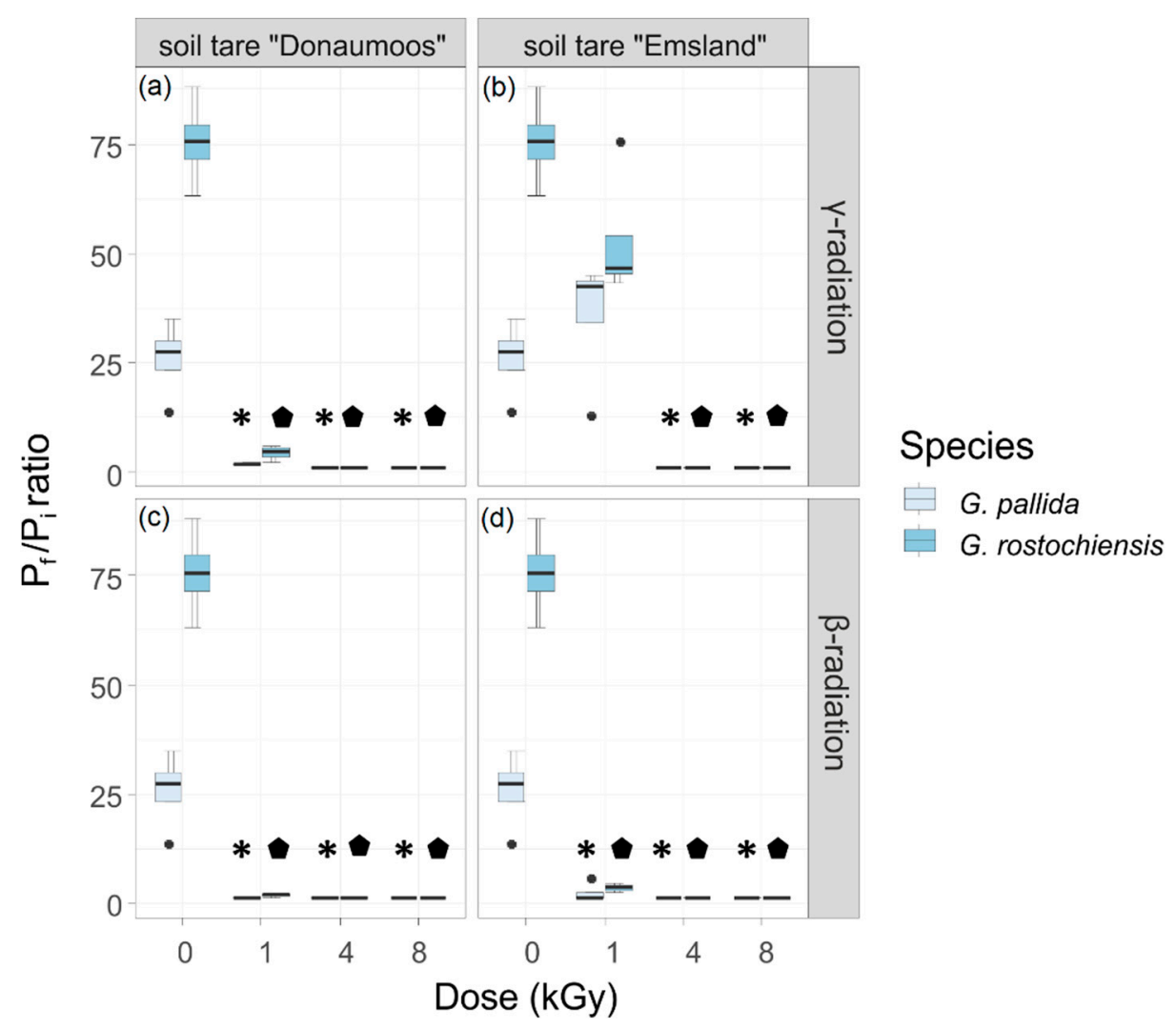

Figure 4. Cyst formation rates for G. pallida and G. rostochiensis from irradiated soil tares. The ratio of newly formed cysts, $\mathrm{P}_{\mathrm{f}}$ (final population) and the number of $\left(\mathrm{P}_{\mathrm{i}}\right)$ initial cysts $(50)$ added to the susceptible potato cultivar "Desireé", at the time of harvest, 15 weeks after potato planting. $P_{\mathrm{i}}$ cysts were either $0,1,4$, or $8 \mathrm{kGy} \gamma(\mathbf{a}, \mathbf{b})$ or $\beta(\mathbf{c}, \mathbf{d})$ irradiated. Globodera pallida and G. rostochiensis. During irradiation, the cysts were placed in soil tare "Emsland" $(\mathbf{b}, \mathbf{d})$ or soil tare "Donaumoos" $(\mathbf{a}, \mathbf{c})$. Data were analysed by the non-parametric Kruskal-Wallis test with a pairwise Wilcoxon post hoc test using adjusted $p$-values. Box-whisker plots display the median values of four replicates. Asterisks indicate the significant differences to the respective non-treated G. pallida and pentagons to the respective non-treated G. rostochiensis controls.

\subsection{Maize Seedling Growth in Irradiated and Non-Irradiated Soils}

The shoot (Figure 5a) and root (Figure 5b) dry weights of the maize seedlings growing for four weeks in irradiated soil was determined. We can observe that in soil tare "Emsland", the dry weight of the shoot is not different between $\beta$ irradiated samples at the dose of 1,4 or $8 \mathrm{kGy}$ and non-treated control soils ( $0 \mathrm{kGy}$ ) (Figure $5 \mathrm{a}$, lower left panel). Soil tare "Donaumoos" showed an increase in shoot weight, with an increasing dose of $\beta$ irradiation. Compared to the respective control, the highest shoot weight can be detected for the maize seedling growing in $8 \mathrm{kGy}$ of $\gamma$ irradiated soil tare B (Figure 5a, lower-right panel) (Dunnett's post-hoc, $p \leq 0.01$ ), while seedlings grown in $8 \mathrm{kGy}$-treated soil tare "Emsland" do not differ from the respective controls (Figure $5 \mathrm{a}$, lower-left panel). Similar observations can be made for the dry weights of the roots in soil tare "Donaumoos" (Figure 5b). A 4 kGy treatment dose of $\gamma$ irradiation correlated with the higher root mass for soil tare "Emsland" (Dunnett's post-hoc, $p \leq 0.05$ ), but had no different growth effects in soil tare "Donaumoos". None of the seedlings grown in the treated soils were dramatically impaired in their growth, in relation to non-treated soils. 


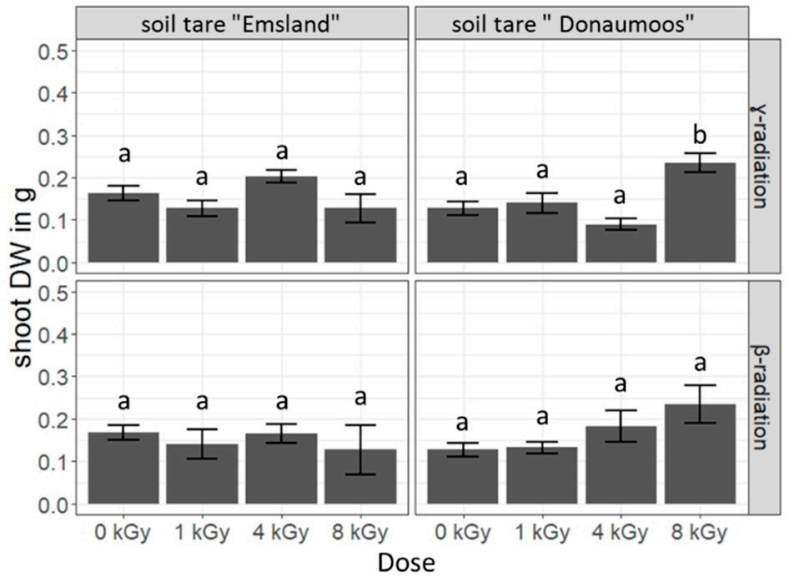

(a)

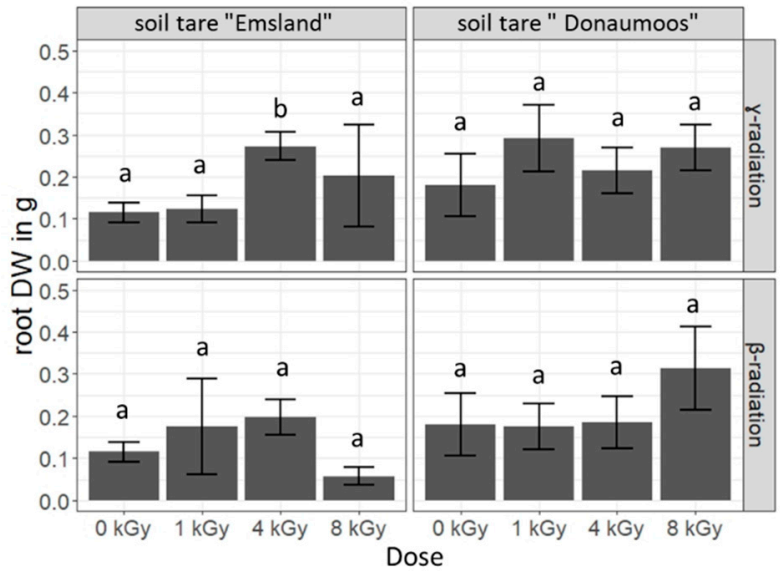

(b)

Figure 5. (a) Shoot and (b) root dry mass of four-week-old Zea mays seedlings growing in $\gamma$ irradiated (upper panels) and $\beta$ irradiated (lower panels) soil tare "Emsland" (left panels) and soil tare "Donaumoos" (right panels). Bar plots indicate the mean values and standard deviation of four replicates per treatment. Data were analysed by ANOVA Dunnett's post hoc test. Lowercase letters indicate the significant differences of shoot (a) and root (b) dry weights compared to their respective controls $(0 \mathrm{kGy}),(p \leq 0.05)$.

\section{Discussion}

The establishment and verification of effective measures for soil tare disinfection from potato cyst nematodes is an important issue that has been the focus of plant health officials for a long time. The results of our study show that $\gamma$ or $\beta$ irradiation treatment of PCN-contaminated soil tares could be an option to suppress PCN hatch and the formation of new cysts without unwanted side effects for soil properties. We found that $4 \mathrm{kGy}$ was the minimum dose of $\gamma$ or $\beta$ irradiation in our experiments to completely inactivate G. pallida and G. rostochiensis. This could be verified for G. pallida and G. rostochiensis cysts directly exposed to irradiation, as well as for cysts embedded in the soil tare matrix. The minimal hatch of juveniles was found only in G. rostochiensis cysts directly exposed to $4 \mathrm{kGy}$ of $\beta$ irradiation, indicating species specific responses. An irradiation of $4 \mathrm{kGy}$ already inactivated PCN eggs and juveniles in treated cysts. Similar findings were observed from Townshend for $5.12 \mathrm{kGy}$ of $\gamma$ irradiated cysts in soil [29].

Interestingly, a dose of $1 \mathrm{kGy}$ of $\gamma$ irradiation did not decrease the hatch of G. pallida juveniles in our study. Instead, we observed a slight increase in the hatching activity for G. rostochiensis cysts. Similar to our study, Townshend observed the stimulation of hatching activity at a dose of $1.28 \mathrm{kGy}$ of $\gamma$ irradiation. A possible explanation might be that the irradiated cyst wall allows an easier diffusion of substances, such as root diffusates, to stimulate the hatching activity. A stimulation of hatching activity by a low dose of $\gamma$ irradiation would allow a targeted disinfection process with a controlled die-off or socalled suicide hatching of juveniles, since the survival of hatched juveniles in the absence of a host plants for more than two weeks is very unlikely $[39,40]$. Although, a number of nematode genera, e.g., root-knot nematode juveniles of Meloidogyne sp., Ditylenchus sp. and Aphelenchoides sp., are able to survive uncomfortable environmental conditions over several months by anabiosis, a breakdown of metabolic processes comparable with quiescence. Normally, potato roots excrete a mixture of chemical compounds that are sensed by the Globodera juveniles as signal to start the hatching process. Some of the hatching factors are well understood in vitro (picrolonic acid, sodium thiocyanate, $\alpha$-solanine and $\alpha$-chaconine) [40-42], but the synthesis in the lab, followed by a successful application under field conditions, has not been described, to date, and might bear some limitations.

Other than the response to $\gamma$ irradiation, $1 \mathrm{kGy}$ of $\beta$ irradiation reduced the hatching activity with a more severe effect for G. pallida. This is likely due to a higher ionising effect 
of $\beta$ than of $\gamma$ irradiation. Albeit, a hatching activity of about $25 \%$ was still found in $\beta$ irradiation-treated G. pallida cysts. A decreased, but incompletely suppressed, hatch of vital juveniles could lead to adverse population dynamics and, therefore, to an unwanted augmentation of PCN populations in potato fields, as shown by Seinhorst [42]. Most studies do not consider hatching activity as an indicator for the success of their treatments, and solely concentrate on nematode reproduction or cyst formation rates after treatments. However, testing hatching activity is less time-consuming and less laborious compared to the infection of susceptible potatoes in bioassays with treated and non-treated cysts. One reason is the potential risk of the underestimation the treatment methods, when solely observing the hatching rates.

We tested both the viability and new cyst formation rates after the treatments. Our results show that G. pallida and G. rostochiensis cysts treated with $1 \mathrm{kGy}$ of $\gamma$ irradiation are still able to release juveniles, but the juveniles fail to produce offspring on a susceptible potato cultivar. It is therefore very unlikely that the remaining hatching activity of about $25 \%$ leads to the establishment of a new population in pest-free potato fields. Townshend also found that most of the juveniles that hatched from cysts that were treated with $1.28 \mathrm{kGy}$ of $\gamma$ irradiation were, per se, not able to form cysts. She speculated that the irradiated juveniles were unable to move through the soil matrix and subsequently unable to penetrate the host roots $[29,30]$. For $G$. rostochiensis, the hatching activity in our study was only slightly reduced, indicating a higher resilience against $\beta$ irradiation than in G. pallida. As a consequence, a treatment with $1 \mathrm{kGy}$ of either $\gamma$ or $\beta$ irradiation does not prevent hatching activity, but neither does it necessarily lead to the formation of cysts.

The $\beta$ irradiation is more ionising and therefore more damaging than $\gamma$ irradiation; however, the main problem is that electrons are less able to penetrate solid matrices than electrons from $\gamma$ irradiation. However, modern high-performance electron acceleration systems are able to reach a penetration depth of $11 \mathrm{~cm}$ in materials with a density of $1 \mathrm{~g} \mathrm{~cm}^{-3}$ (personal communication, Dr. T. Schröder). Soil densities vary between $0.3 \mathrm{~g} \mathrm{~cm}^{-3}$ for high organic matter soils and $1.6 \mathrm{~g} \mathrm{~cm}^{-3}$ for sandy and loamy soils, and would therefore restrict the soil depth for irradiation treatment. In our experiments, we showed for the first time that $\beta$ irradiation on two different soil tares is also suitable for soil disinfection from PCNs up to a depth of at least $2.5 \mathrm{~cm}$. The reproduction of both nematode species, G. pallida and $G$. rostochiensis, placed as cysts in the soil tares was drastically reduced after they received $1 \mathrm{kGy}$ of $\beta$ irradiation. Evidently, the soil properties in our study were less decisively selected for the success of $\beta$ irradiation than for the $\gamma$ irradiation treatment, indicating a more flexible use of this technique for soil tare treatment. However, soil properties, such as density, humidity and soil grain size, should be considered when irradiation is applied. A deeper understanding of how these parameters influence the irradiation treatment is needed to guarantee successful and reliable disinfection.

Comparing irradiation to other effective soil disinfection measures, the specific control of organism groups by defined $\gamma$ or $\beta$ irradiation doses [33,34] is a clear advantage over the treatment of soil tares with steam or by autoclaving processes. Moreover, unlike with the use of chemical treatments, no toxic residues remain in the soils. The unwanted effects on soil structure, as observed in steamed or autoclaved soils, are completely missing and the dynamics of the loss or unavailability of major nutrients might not be affected; even high doses of $\gamma$ irradiation at $35 \mathrm{kGy}$ do not affect the physicochemical properties of the treated soils [43]. Our findings also reflect that the maize seedling growth in irradiated soils was similar to the growth in untreated soils.

To summarise, in our studies both, $\gamma$ and $\beta$ irradiation showed an efficient inactivation of PCNs from soil tares. In comparison to other phytosanitary measures, in the light of efficacy and costs, soil tare treatment with $\gamma$ and $\beta$ irradiation is a worthwhile option that should be taken into consideration. However, before a possible implementation of this method, the technical constraints in plant constructions suitable for practical applications need to be solved. Attempts to downsize radiation facilities are already under development and prototypes are available. In addition, further experiments with a comprehensive set 
of different tare soil types and soil volumes will help to determine the advantages and limitations for $\beta$ and $\gamma$ irradiation as phytosanitary measures against PCNs.

Author Contributions: Conceptualisation, S.K. and M.D.; methodology, S.K. and B.B.; software, B.B.; validation, S.K., M.D. and B.B.; formal analysis, B.B.; investigation, B.B. and L.S.; resources, S.K.; data curation, B.B.; writing-original draft preparation, B.B.; writing-review and editing, S.K., M.D. and L.S.; visualisation, B.B.; project administration, S.K., M.D. and B.B.; funding acquisition, S.K. and M.D. All authors have read and agreed to the published version of the manuscript.

Funding: This research was funded by The Federal Office for Agriculture and Food (BLE), BÖLN grant number FKZ 2815NA120. We thank the BLE for funding this research.

Institutional Review Board Statement: Not applicable.

Informed Consent Statement: Not applicable.

Data Availability Statement: The data presented in this study are available on request from the corresponding author.

Acknowledgments: We are very thankful to Katja Reimann and Christine-Maria Gottwald for technical assistance and the potato processing companies for providing potato soil tare. We thank Synergy Health Radeberg GmbH, a STERIS company, Radeberg Deutschland for advising and performing the irradiation treatments.

Conflicts of Interest: The authors declare no conflict of interest.

\section{References}

1. EPPO. PM 7/40 (4) Globodera rostochiensis and Globodera pallida. EPPO Bull. 2017, 47, 174-197. [CrossRef]

2. Sullivan, M.J.; Inserra, R.N.; Franco, J.; Moreno-Leheude, I.; Greco, N. Potato cyst nematodes: Plant host status and their regulatory impact. Nematropica 2007, 37, 193-202.

3. CABI. Globodera pallida (White Potato Cyst Nematode). Available online: https://www.cabi.org/cpc/datasheet/27033 (accessed on 29 March 2021).

4. CABI. Globodera rostochiensis (Yellow Potato Cyst Nematode). Available online: https://www.cabi.org/cpc/datasheet/27034 (accessed on 29 March 2021).

5. Mburu, H.; Cortada, L.; Haukeland, S.; Ronno, W.; Nyongesa, M.; Kinyua, Z.; Bargul, J.L.; Coyne, D. Potato cyst nematodes: A new threat to potato production in East Africa. Front. Plant Sci. 2020, 11, 670. [CrossRef] [PubMed]

6. Koirala, S.; Watson, P.; McIntosh, C.S.; Dandurand, L.-M. Economic impact of Globodera pallida on the Idaho economy. Am. J. Potato Res. 2020, 97, 214-220. [CrossRef]

7. Whitehead, A.G.; Turner, S.J. Management and regulatory control strategies for potato cyst nematodes (Globodera rostochiensis and Globodera pallida). In Potato Cyst Nematodes, Biology, Distribution and Control; CABI Publishing: Wallingford, UK, 1998 ; pp. 135-152.

8. Niere, B.; Krüssel, S.; Osmers, K. Auftreten einer außergewöhnlich virulenten Population der Kartoffelzystennematoden. J. Kulturpflanz. 2014, 66, 426-427.

9. Anonymous. Council Directive 2007/33/EC of 11 June 2007 on the control of potato cyst nematodes and repealing Directive 69/465/EEC. Off. J. Eur. Union 2007, L 156, 12-23.

10. Duncan, L.W.; Moens, M. Migratory endoparasitic nematodes. In Plant Nematology; CABI Publishing: Wallingford, UK, 2006; pp. 123-152.

11. Winlsow, R.D.; Willis, R.J. Nematode diseases of potatoes. II. Potato cyst nematode, Heterodera rostochiensis. In Economic Nematology; Webster, J., Ed.; Academic Press: New York, NY, USA, 1972; pp. 18-34.

12. Proctor, B.E.; Lockhart, E.E.; Goldblith, S.A.; Grundy, A.V.; Tripp, G.E.; Karel, M.; Brogle, R.C. The use of ionizing radiations in the eradication of insects in packaged military rations. Food Technol. 1954, 8, 536-540.

13. Wit, A.H.K.; van de Vrie, M. Gamma radiation for post harvest control of insects and mites in cutflowers. Rijksuniv. Fac. Landbouwwet. Gent 1985, 50, 697-704.

14. Dohino, T.; Tanabe, K.; Hayashi, T. Comparison of lethal effects of electron beams and gamma rays on eggs of two spotted spider mite, Tetranychus urticae Koch (Acari: Tetranychidae). Res. Bull. Plant Prot. Serv. Jpn. 1994, 30, 69-73.

15. Terrien, J. News from the Bureau International des Poids et Mesures. Metrologia 1975, 11, 179-183. [CrossRef]

16. Jackson, N.E.; Corey, J.C.; Frederick, L.R.; Picken, J.C., Jr. Gamma irradiation and the microbial population of soils at two water contents. Soil Sci. Soc. Am. J. 1967, 31, 491-494. [CrossRef]

17. Dertinger, H.; Jung, H. Molekulare Strahlenbiologie: Vorlesungen über die Wirkung Ionisierender Strahlen auf Elementare Biologische Objekte; Springer: Berlin/Heidelberg, Germany, 1969; ISBN 9783642951169.

18. Stolz, W. Strahlensterilisation: Grundlagen und Anwendung in Medizin und Pharmazie; J.A. Barth: Leipzig, Germany, 1972.

19. Schiller, S.; Heisig, U.; Panzer, S. Elektronenstrahltechnologie; 1. Auflage; Technik GmbH: Stuttgart, Germany, 1977. 
20. Lobo, V.; Patil, A.; Phatak, A.; Chandra, N. Free radicals, antioxidants and functional foods: Impact on human health. Pharmacogn. Rev. 2010, 4, 118. [CrossRef] [PubMed]

21. Arunachalam, G.; Oblisami, G.; Rangaswami, G. Effect of gamma radiation on certain microbial and chemical properties of two soil types. Madras Agric. J 1974, 61, 992-996.

22. Edwards, C.A. Effects of gamma irradiation on populations of soil invertebrates. In Symposium on Radioecology: US Atomic Energy Commission Report CONF-670503; Nelson, D.J., Evans, F.C., Eds.; U.S. Department of Energy Office of Scientific and Technical Information: Oak Ridge, TN, USA, 1969; pp. 68-77.

23. Myers, R.F. The sensitivity of some plant-parasitic and free-living nematodes to gamma and x-irradiation. Nematologica 1960, 5 , 56-63. [CrossRef]

24. Chinnasri, B.; Moy, J.H.; Sipes, B.S.; Schmitt, D.P. Effect of gamma-irradiation and heat on root-knot nematode, Meloidogyne javanica. J. Nematol. 1997, 29, 30-34.

25. Thompson, J.P. Treatments to eliminate root-lesion nematode (Pratylenchus Thornei Sher \& Allen) from a vertisol. Nematologica 1990, 36, 123-127. [CrossRef]

26. Maremonti, E.; Eide, D.M.; Oughton, D.H.; Salbu, B.; Grammes, F.; Kassaye, Y.A.; Guédon, R.; Lecomte-Pradines, C.; Brede, D.A. Gamma radiation induces life stage-dependent reprotoxicity in Caenorhabditis elegans via impairment of spermatogenesis. Sci. Total Environ. 2019, 695, 133835. [CrossRef]

27. Ishibashi, $\mathrm{N}$. The increase in male adults by gamma-ray irradiation in the root-knot nematode, Meloidogyne Incognita Chitwood. Nematologica 1965, 11, 361-369. [CrossRef]

28. Evans, K. The effects of gamma radiation on Heterodera rostochiensis. Nematologica 1970, 16, 284-294. [CrossRef]

29. Townshend, J.L. Gamma irradiation of Heterodera schachtii 1. Nematologica 1967, 13, 586-592. [CrossRef]

30. Weischer, B. Die Wirkung ionisierender Strahlen auf die Entwicklung von Heterodera rostochiensis und H. schachtii 1. Nematologica 1957, 2, 300-305. [CrossRef]

31. Karnkowski, W.; Ignatowicz, S. Development of the Yellow Potato Cyst Nematode Globodera rostochiensis (Woll.) on Potatoes after Gamma Irradiation of Cysts; No. IAEA-TECDOC-1082; International Nuclear Information System: Vienna, Austria, 1999 ; pp. $123-127$.

32. Roeder, O.; Knappe, U. Die Elektronenbehandlung, eine physikalische Alternative zur chemischen Beizung von Saatgut. In Behandlung und Lagerung von Eichensaatgut: Situation und Darstellung Aktueller Forschungsarbeiten; Kolloquium am 24. April 1996 in Braunschweig = Treatment and storage of oak seeds; Wulf, A., Ed.; Parey: Berlin, Germany, 1997; ISBN 382633163X.

33. Buchan, D.; Moeskops, B.; Ameloot, N.; de Neve, S.; Sleutel, S. Selective sterilisation of undisturbed soil cores by gamma irradiation: Effects on free-living nematodes, microbial community and nitrogen dynamics. Soil Biol. Biochem. 2012, 47, 10-13. [CrossRef]

34. McNamara, N.P.; Black, H.; Beresford, N.A.; Parekh, N.R. Effects of acute gamma irradiation on chemical, physical and biological properties of soils. Appl. Soil Ecol. 2003, 24, 117-132. [CrossRef]

35. Eno, C.F.; Popenoe, H. The effect of gamma radiation on the availability of nitrogen and phosphorus in soil. Soil Sci. Soc. Am. J. 1963, 27, 299. [CrossRef]

36. Ogwu, M.C.; Kerfahi, D.; Song, H.; Dong, K.; Seo, H.; Lim, S.; Srinivasan, S.; Kim, M.K.; Waldman, B.; Adams, J.M. Changes in soil taxonomic and functional diversity resulting from gamma irradiation. Sci. Rep. 2019, 9, 7894. [CrossRef]

37. EPPO. PM 7/129 (1) DNA barcoding as an identification tool for a number of regulated pests. EPPO Bull. 2016, 46, 501-537. [CrossRef]

38. Müller, J.; Rumpenhorst, H.J. Die Prüfung von Pflanzen auf Ihre Widerstandsfähigkeit Gegen Schadorgansimen in der Biologischen Bundesanstalt: Teil 1: Prüfung von Kulturplfanzen auf Resistenz Gegen Pflanzenparasitäre Nematoden; Wiegandt, Hempel \& Parey: Berlin, Germany, 2000; Volume 372.

39. Perry, R.N.; Wright, D.J. The Physiology and Biochemistry of Free-Living and Plant-Parasitic Nematodes; CABI Publishing: Wallingford, $\mathrm{UK}, 1998$.

40. Robinson, M.P.; Atkinson, H.J.; Perry, R.N. The influence of temperature on the hatching, activity and lipid utilization of second stage juveniles The influence of temperature on the hatching, activity and lipid utilization of second stage juveniles of the potato cyst nematodes Globodera rostochiensis and G. pallida. Rev. Nematol. 1987, 10, 349-354.

41. Byrne, J.; Twomey, U.; Maher, N.; Devine, K.J.; Jones, P.W. Detection of hatching inhibitors and hatching factor stimulants for golden potato cyst nematode, Globodera rostochiensis, in potato root leachate. Ann. Appl. Biol. 1998, 132, 463-472. [CrossRef]

42. Seinhorst, J.W. The relation between nematode density and damage to plants. Nematologica 1965, 11, 137-154. [CrossRef]

43. Gautier, C.; Martinez, L.; Fournet, S.; Montarry, J.; Yvin, J.-C.; Nguema-Ona, E.; Guillerm-Erckelboudt, A.-Y.; Piriou, C.; Linglin, J.; Mougel, C.; et al. Hatching of Globodera pallida induced by root exudates is not influenced by soil microbiota composition. Front. Microbiol. 2020, 11, 536932. [CrossRef] 